\title{
Rational Design of pH-Controlled DNA Strand Displacement
}

\author{
Alessia Amodio, ${ }^{\dagger, \ddagger, \#}$ Bin Zhao, ${ }^{\S, \#}$ Alessandro Porchetta, ${ }^{\dagger, \#}$ Andrea Idili, ${ }^{\dagger}$ Matteo Castronovo, ${ }^{\ddagger}, \|, \perp$ \\ Chunhai Fan, ${ }^{\S}$ and Francesco Ricci ${ }^{*} \dagger$ \\ ${ }^{\dagger}$ Dipartimento di Scienze e Tecnologie Chimiche, University of Rome, Tor Vergata, Via della Ricerca Scientifica, 00133, Rome, Italy \\ ${ }^{\ddagger}$ School of Nanotechnology, Department of Physics, University of Trieste, Via Valerio 2, 34127 Trieste, Italy \\ ${ }^{\S}$ Division of Physical Biology, and Bioimaging Center, Shanghai Synchrotron Radiation Facility, CAS Key Laboratory of Interfacial \\ Physics and Technology, Shanghai Institute of Applied Physics, Chinese Academy of Sciences, Shanghai 201800, China \\ "Department of Medical and Biological Science, University of Udine, Piazzale Kolbe 4, 3310, Udine, Italy \\ ${ }^{\perp}$ Department of Biology, Temple University, 1900 N. 12th Street, Philadelphia, Pennsylvania 19122, United States
}

\section{Supporting Information}

ABSTRACT: Achieving strategies to finely regulate with biological inputs the formation and functionality of DNAbased nanoarchitectures and nanomachines is essential toward a full realization of the potential of DNA nanotechnology. Here we demonstrate an unprecedented, rational approach to achieve control, through a simple change of the solution's $\mathrm{pH}$, over an important class of DNA association-based reactions. To do so we took advantage of the $\mathrm{pH}$ dependence of parallel Hoogsteen interactions and rationally designed two triplex-based DNA strand displacement strategies that can be triggered and finely regulated at either basic or acidic pHs. Because $\mathrm{pH}$ change represents an important input both in healthy and pathological biological pathways, our findings can have implication for the development of DNA nanostructures whose assembly and functionality can be triggered in the presence of specific biological targets.

$\mathrm{D}$ NA nanotechnology uses DNA (or nucleic acids) as a versatile material to rationally engineer tools and molecular devices that can find a multitude of different applications (e.g., in vivo imaging, clinical diagnostics, drugdelivery, etc.). ${ }^{1}$ An exciting development of this field, namely structural DNA nanotechnology, is characterized by the use of DNA to build complex nanometer-scale structures, often referred to as DNA origami or DNA tiles. ${ }^{2}$ With its simple base-pairing code and its nanoscale dimension, in fact, DNA appears as the perfect building block to assemble and engineer complex molecular architectures with unique accuracy and precision. Similarly, the possibility to quantitatively predict and simulate DNA thermodynamics interactions has allowed to expand the horizons of DNA nanotechnology into the construction of programmable and autonomous DNA-based nanodevices that can be engineered to have different functions. $^{1-3}$

In order to create these complex nanostructures with enough precision and to engineer functional DNA nanodevices it is crucial to strictly control the thermodynamics and the kinetics with which DNA strands interact and hybridize with each other. A beautiful example of such possibility is represented by the toehold-mediated (or toehold-exchange) DNA strand displacement, a process through which two strands hybridize with each other displacing one (or more) prehybridized strands. ${ }^{4}$ Such process, pioneered by Yurke, and later expanded by Zhang, Winfree, and Yurke himself, has been systematically applied to engineer functional DNA nanodevices. These include molecular motors, ${ }^{3 a, 5}$ tweezers, ${ }^{6,7}$ autonomous nanomachines, ${ }^{8,9}$ circuits, ${ }^{10}$ and catalytic amplifiers. ${ }^{11}$ Because it can allow a specific kinetic control of several reaction pathways, DNA strand displacement has also found applications in the construction of DNA-based nanostructures and origami. ${ }^{4 \mathrm{~b}, 12}$

Despite the advantages represented by strand-displacement to build and engineer complex and functional DNA structures in a controlled way, additional features might help in improving the programmability of this process. For example, we note that, using the conventional approach, once the invading strand (i.e., the strand that activates strand-displacement) is added to the reaction mixture, it is difficult to implement an additional external control to further regulate the process. That is, the strand-displacement reaction performs equally well in different environments ( $\mathrm{pH}$, temperature, etc.). While this property can be an advantage for some applications, ${ }^{13}$ it can be a limitation for others, as in some cases it could be preferable to exogenously control the entire displacement process. In this context, despite in recent years the DNA strand displacement process has seen a widespread application, only few examples have been reported that allow to activate strand displacement with small molecules ${ }^{14}$ (i.e., $\mathrm{Hg}$ (II) metal ions and adenosine) or at acidic $\mathrm{pHs}$ using imotif, ${ }^{15}$ G-quadruplex, ${ }^{15}$ and triplex-forming strands. ${ }^{16}$ More recently, light-controlled strand displacement reactions were also demonstrated using photoregulated oligonucleotides. ${ }^{17}$

Motivated by the above arguments, we have rationally designed here two programmable, toehold-based DNA strand displacement strategies that can be triggered and controlled by a simple $\mathrm{pH}$ change. We did so by taking advantage of the wellcharacterized $\mathrm{pH}$ sensitivity of the parallel Hoogsteen $(\mathrm{T}, \mathrm{C})$ motif in triplex DNA. ${ }^{18,19}$ The sequence-specific formation of a CGC parallel triplet through the formation of Hoogsteen interactions, in fact, requires the protonation of the $\mathrm{N} 3$ of

Received: August 19, 2014 
cytosine in the third strand in order to form (average $\mathrm{p} K_{\mathrm{a}}$ of protonated cytosines in triplex structure is $\approx 6.5) .^{20}$ For this reason, DNA strands containing cytosines can only form a triplex structure at acidic $\mathrm{pHs}$.

More specifically, we designed two complementary strategies, for which DNA-strand displacement is activated either at basic pHs (strategy \#1) or at acidic/neutral pHs (strategy \#2) (Figure $1 \mathrm{a}$ and $1 \mathrm{~b}$, respectively). In the first strategy $\left(\mathrm{OH}^{-}\right.$-activated

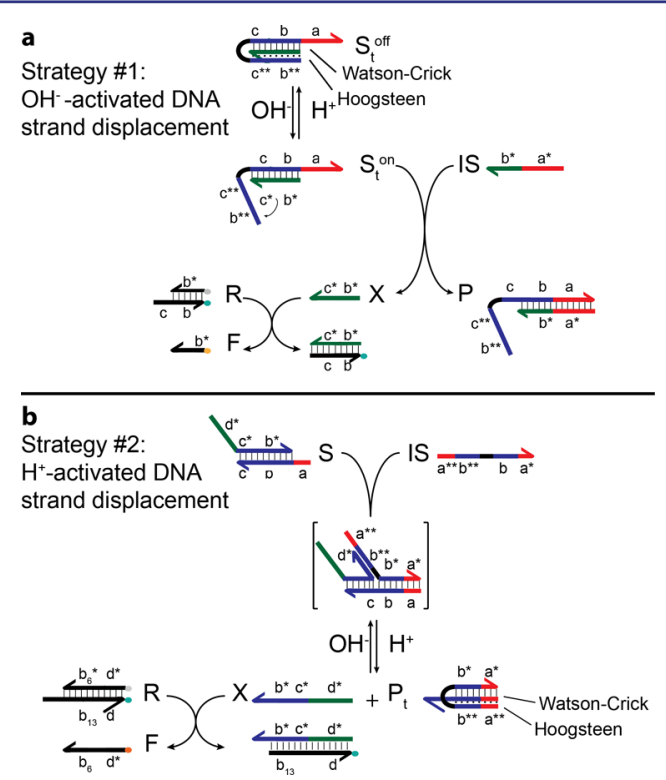

Figure 1. The pH-controlled, toehold-based DNA strand displacement strategies. (a) In the first strategy we have designed a DNA strand displacement that is activated at basic $\mathrm{pHs}\left(\mathrm{OH}^{-}\right.$-activated stranddisplacement). To do this, we have used a clamp-like DNA strand that, under acidic $\mathrm{pHs}$, forms a triplex inactive complex $\left(\mathrm{S}_{\mathrm{t}}\right.$ off $)$ with the strand to be released (X). The additional Hoogsteen interactions in this triplex structures provide an increased stabilization to the complex that prevents strand displacement upon Invading Strand (IS) addition. At basic $\mathrm{pHs}$, the destabilization of the Hoogsteen interactions leads to an active complex $\left(\mathrm{S}_{\mathrm{t}}{ }^{\text {on }}\right)$ characterized by a simple duplex conformation. Because this structure is not stabilized anymore by Hoogsteen interactions, it can undergo displacement through a classic toeholdexchange mechanism. (b) In the second strategy we designed a toeholdbased DNA strand displacement process that is activated at acidic/ neutral $\mathrm{pHs}\left(\mathrm{H}^{+}\right.$-activated strand displacement). To do this, we have designed an IS comprised of a triplex-competent DNA sequence that can bind through a clamp-like mechanism a strand in the complex $\mathrm{S}$. Under basic conditions, this IS can only form Watson-Crick interactions and, due to he content and length of the toehold-binding $\left(\mathrm{a}^{*}\right)$ and invading $\left(\mathrm{b}^{*}\right)$ portion, strand displacement process is unfavored. In contrast, at acidic pHs, triplex formation through Hoogsteen interactions provides an additional energetic contribution that allows strand displacement to occur. In this study the progress of strand displacement is always followed using an optically labeled reporter complex $(\mathrm{R})$ that stoichiometrically reacts with the released strand $(\mathrm{X})$ to produce an unquenched fluorophore-labeled single strand DNA molecule $(\mathrm{F})$. We note that the reaction between the reporter complex $(\mathrm{R})$ and the released strand $(\mathrm{X})$ is not sensitive to $\mathrm{pH}$ in the $\mathrm{pH}$ range we have investigated (Figures SI1 and SI2) and does not directly take part to the strand displacement reaction. ${ }^{4}$ In this paper, domains are represented by letters. Starred letters (*) represent domains complementary to the domains denoted by unstarred letters and forming classic Watson-Crick base pairings. Double starred letters $(* *)$ represent triplex-forming domains that form Hoogsteen interactions with duplex formed by the domains denoted by starred (*) and unstarred letters. strand displacement), a clamp-like, triplex-forming DNA prevents strand displacement at acidic $\mathrm{pHs}$ (conditions at which triplex formation is favored) (Figure 1a), while at basic pHs (when Hoogsteen interactions are destabilized) a classic strand-displacement reaction is observed. In the second strategy $\left(\mathrm{H}^{+}\right.$-activated strand displacement), in contrast, the invading strand (IS) contains a clamp-like triplex forming portion. Only under $\mathrm{pH}$ conditions (acid/neutral) at which Hoogsteen interactions can form and we observe the strand displacement process (Figure $1 \mathrm{~b}$ ).

Both strategies rely on the use of $\mathrm{pH}$-dependent clamp-like conformational switches (Figure 1) that lead to triplex formation. ${ }^{18}$ In the first strategy triplex formation is utilized to lock the strand that would be otherwise released in the presence of the IS. In the second strategy, in contrast, clamp-like triplex formation triggers strand displacement. As a first characterization of both strategies, we have thus studied the $\mathrm{pH}$-dependent stability of the corresponding clamp-like triplex complexes. To do this we have initially studied the $\mathrm{pH}$-dependent stability of the triplex complex $\left(S_{t}{ }^{\text {off }}\right)$ in strategy \#1 (Figure 2a). More
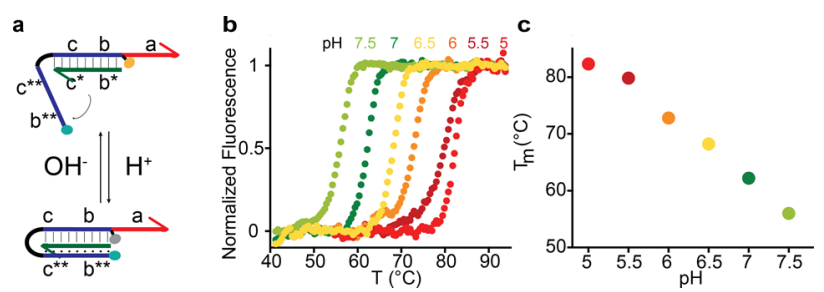

Figure 2. The pH-dependent clamp-like triplex DNA formation. (a) Folding/unfolding of the triplex complex of strategy \#1 (see Figure 1a) is monitored here through a $\mathrm{pH}$-insensitive FRET pair located in an internal position $(\mathrm{Cy} 3)$ and at the $5^{\prime}$-end $(\mathrm{Cy} 5)$ of the clamp-like strand. (b) Shown are the melting denaturation curves of the complex $S_{t}(20$ $\mathrm{nM}$ ) obtained at different $\mathrm{pH}$ values in a $0.01 \mathrm{M}$ Tris buffer solution $+0.01 \mathrm{M} \mathrm{MgCl}_{2}$. (c) At a pH at which triplex formation is favored $(\mathrm{pH}=$ 5 ), the melting temperature of the complex is $82.3{ }^{\circ} \mathrm{C}$. As the acidity of the solution is progressively reduced to reach $\mathrm{pH} 7.5$, at which triplex formation is unfavored, the complex is progressively destabilized until it reaches a melting temperature of $56.0^{\circ} \mathrm{C}$.

specifically, we have used a dual labeled clamp-like triplex forming strand, and after hybridization to a target DNA oligo, we have performed thermal denaturation of the so-formed complex at different $\mathrm{pHs}$ (Figure 2b). As expected, under acidic $\mathrm{pHs}$, a condition at which triplex formation is favored, ${ }^{18}$ the overall stability of the complex is improved. For example, at a $\mathrm{pH}$ low enough to allow triplex formation $(\mathrm{pH}=5)$, the denaturation of the complex occurs at very high temperatures (i.e., $T_{\mathrm{m}}=82.3$ $\left.{ }^{\circ} \mathrm{C}\right)$. In contrast, under $\mathrm{pH}$ values at which triplex formation is unfavored $(\mathrm{pH}=7.5)$, the denaturation of the complex occurs at a much lower temperature $\left(T_{\mathrm{m}}=56.0^{\circ} \mathrm{C}\right)$ (Figure $\left.2 \mathrm{c}\right)$. A similar $\mathrm{pH}$ dependence has been observed with the clamp-like strands of strategy \#2 (Figure SI3). We also note that at acidic $\mathrm{pH}$ the possible alternative i-motif ${ }^{21}$ that the triplex-forming strand (in Figure 1: $\mathrm{c}^{* *} \mathrm{~b}^{* *}$ ) could form does not affect the $\mathrm{pH}$ dependence of our system. These results demonstrate that the clamp-like triplex formation based on Hoogsteen interactions offers highly efficient and tunable $\mathrm{pH}$ regulation, which could be suitable toward the realization of $\mathrm{pH}$-dependent DNA-based molecular devices.

Triplex formation in both the strategies we present here allows to rationally control the displacement process by simply changing the solution's $\mathrm{pH}$. For example, for strategy \#1 
$\left(\mathrm{OH}^{-}\right.$-activated strand displacement), at $\mathrm{pH} 8$ (a pH at which triplex formation is unfavored), strand displacement proceeds with a fast kinetic upon IS addition (Figure 3a, top). At pH 5, in contrast, which is acidic enough for the clamp-like strand to form a triplex, inactive complex $\left(S_{t}\right.$ off $)$ (see Figure $2 a$ ), the addition of the IS does not result in any significant signal change (Figure 3a, bottom), suggesting that no displacement occurs. Such $\mathrm{pH}$ dependent strand displacement process is observed over a wide range of IS concentrations. A conventional strand displacement

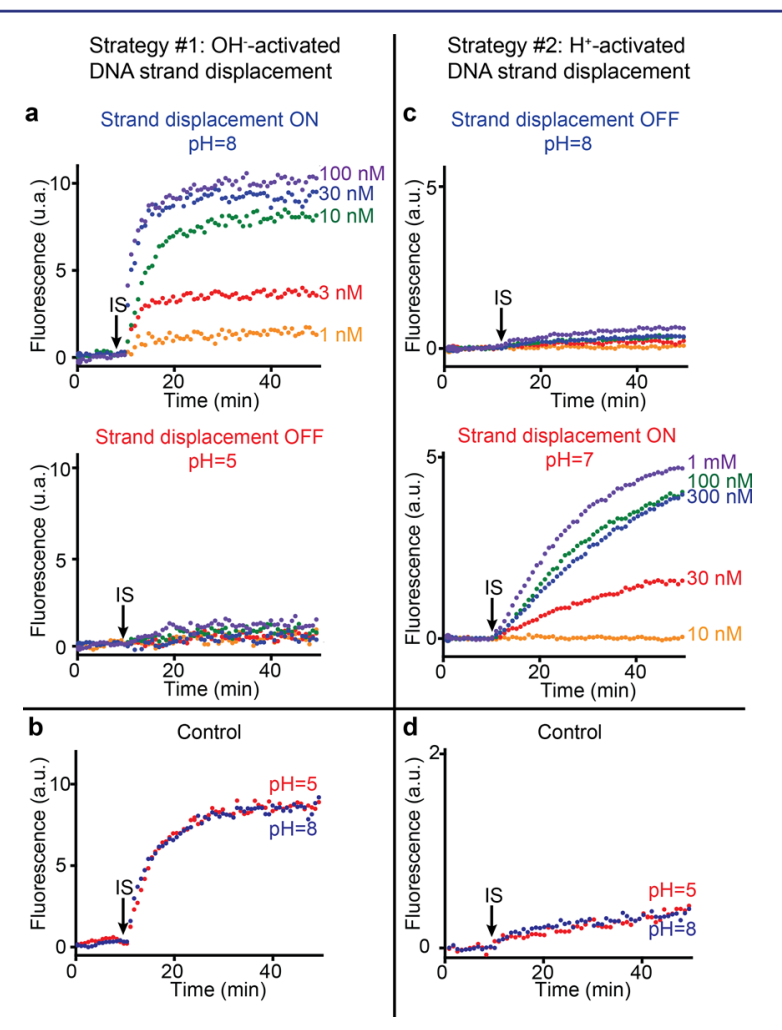

Figure 3. $\mathrm{OH}^{-}$- and $\mathrm{H}^{+}$-activated toehold-based DNA strand displacement. (Left) In the first strategy we dissected here $\left(\mathrm{OH}^{-}\right.$-activated strand displacement), strand displacement is only observed at basic $\mathrm{pHs}$ (a, top), while under acidic $\mathrm{pHs}$ (a, bottom) triplex formation leads to a very stable complex $\left(S_{t}\right.$ off , Figure 1a) that prevents strand displacement. Such $\mathrm{pH}$ dependence is observed over a wide range of IS concentrations (from 1 to $100 \mathrm{nM}$ ). A control toehold-based DNA strand displacement that uses the same sequences except for the fact that it lacks the terminal triplex-forming portion $\left(\mathrm{b}^{* *}\right.$ and $\left.\mathrm{c}^{* *}\right)$ is, as expected, independent of $\mathrm{pH}$ (b). Here, we used an IS with a toehold-binding portion ( $\mathrm{a}^{*}$ in Figure 1a) of 15 bases and an invading portion (b* in Figure 1a) of 10 bases. Electrophoresis experiments (PAGE) confirm such $\mathrm{pH}$ dependency (Figure SI9). (Right) In the second strategy we have used here $\left(\mathrm{H}^{+}\right.$-activated strand displacement) the addition of the IS under basic conditions $(\mathrm{pH} 8)$ does not result in any significant strand displacement reaction (c, top). Strand displacement reaction is triggered at acidic $\mathrm{pHs}$, due to the formation of a triplex complex (c, bottom). Also in this case, such $\mathrm{pH}$ dependence is observed over a wide range of IS concentrations (from $10 \mathrm{nM}$ to $1 \mu \mathrm{M}$ ). A control IS with the same toehold-binding and invading domains as the one used above but lacking the triplex forming portion $\left(\mathrm{a}^{* *}\right.$ and $\left.\mathrm{b}^{* *}\right)$ does not lead to any displacement reaction over the entire $\mathrm{pH}$ range we have investigated (d). Fluorescence signals shown here have been subtracted from the background signal. Strand displacement in both these strategies is followed by fluorescence measurements obtained in a solution of complex $S(10 \mathrm{nM})$ in the presence of reporter $\mathrm{R}(30 \mathrm{nM})$ after the addition of the IS at a concentration of $30 \mathrm{nM}$ in a $0.01 \mathrm{M}$ Tris buffer $+0.01 \mathrm{M} \mathrm{MgCl}_{2}$, at 25 ${ }^{\circ} \mathrm{C}$. toehold-exchange process (thus based on a complex that cannot form a triplex structure) is independent of $\mathrm{pH}$ and occurs with very similar kinetics in the entire $\mathrm{pH}$ range we have investigated (Figure $3 \mathrm{~b}$ ) and over a wide range of IS concentrations (Figure SI4). ${ }^{4 c}$ Of note, this duplex-only control complex (used here for a comparison) has the same sequence of that used in the $\mathrm{OH}^{-}$activated strand displacement process except that it lacks the domains $b^{* *}$ and $c^{* *}$, i.e., the portions able to form the triplex (see Figure 1a and Materials).

Because triplex stability can be tuned at different $\mathrm{pHs}$ (see Figure 2), we can achieve a gradual inhibition/activation of the strand displacement process by gradually changing the solution's $\mathrm{pH}$ (Figure SI5). As expected, intermediate kinetics are observed under $\mathrm{pH}$ conditions at which triplex/duplex equilibrium is more balanced (around $\mathrm{pH} 7$ ). Again, such tunable behavior is observed over a wide concentration range of IS (i.e., from 1 to $100 \mathrm{nM}$ ) (Figure SI6). Different degree of inhibition can also be achieved varying the IS length (Figures SI7 and SI8). For example, by changing the $\mathrm{pH}$ of the solution from $\mathrm{pH} 8$ to 5 we can observe only a partial inhibition of the displacement reaction using an IS containing an invading domain of 12 bases (Figure SI7). With the same $\mathrm{pH}$ change we observe a complete inhibition of the displacement process when we use shorter invading domains (i.e., 10 and 8 bases) (Figure SI7). A similar trend is observed at different $\mathrm{pH}$ values and with different concentrations of IS (Figure SI8).

In the second strategy $\left(\mathrm{H}^{+}\right.$-activated DNA strand displacement) we present here, $\mathrm{pH}$-dependent triplex formation triggers strand displacement. Of note, in this case, contrarily to the first strategy described above, the triplex forming portion is within the IS (Figure 1b). At $\mathrm{pH} 8$ (triplex destabilizing condition), the addition of the IS does not result in any significant fluorescence signal increase (Figure 3c, top). In contrast, at $\mathrm{pH} 7$ (a pH low enough to form already a triplex complex), the addition of the IS successfully leads to the strand displacement reaction (Figure 3c, bottom). In this $\mathrm{H}^{+}$-activated strategy, a $\mathrm{pH}$ change of just one unit (from $\mathrm{pH} 8$ to 7 ) will be sufficient to activate the strand displacement process. Similarly to what we have achieved with the $\mathrm{OH}^{-}$-activated strategy, also in this case the $\mathrm{pH}$-dependent behavior is observed over a wide range of IS concentration (from $30 \mathrm{nM}$ to $1 \mu \mathrm{M}$, see Figure SI10). A control experiment obtained using an IS with the same sequence used above except that it lacks the domains $\mathrm{a}^{* *}$ and $\mathrm{b}^{* *}$, i.e., the portion necessary to form the triplex (see Figure $1 \mathrm{~b}$ and Materials) shows that the displacement process is independent of $\mathrm{pH}$, as expected. More specifically, we did not observe any significant displacement signal over the entire $\mathrm{pH}$ range investigated (from 5 to 8 ) and over the same IS concentration range (from $30 \mathrm{nM}$ to $1 \mu \mathrm{M}$ ) (Figures 3d and SI11).

Both the strategies we have dissected here allow an external control over the strand displacement process. We further demonstrate this by adding the IS under initial inhibiting conditions (Figure 4) for both strategies. The addition of the IS under these conditions does not lead to any significant strand displacement (Figure 4, red lines). Upon addition of either $\mathrm{OH}^{-}$ (Figure $4 \mathrm{a}$ ) or $\mathrm{H}^{+}$(Figure $4 \mathrm{~b}$ ), we were able to activate both processes, and we observed an immediate increase of the fluorescence signals associated with the strand displacement reactions (Figure 4, blue curves). A similar feature has been observed over a wide IS concentration range (Figure SI12).

Here we have rationally designed triplex-based DNA strand displacement reactions that, in contrast to previous $\mathrm{pH}$ controlled examples, can be triggered/activated at both basic 


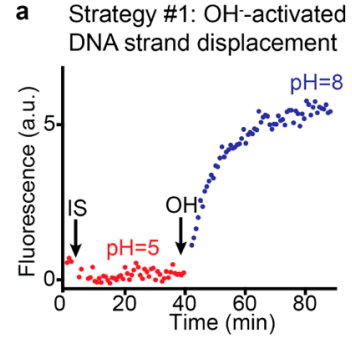

b Strategy \#2: $\mathrm{H}^{+}$-activated DNA strand displacement

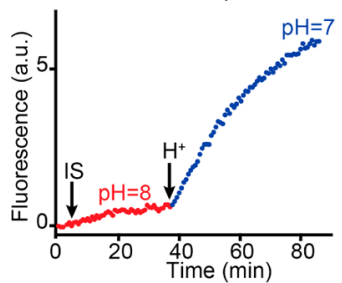

Figure 4. Toehold-based DNA strand displacement in the triplex-DNA based strategies we propose here can be triggered by changing the solution's $\mathrm{pH}$. Under inhibiting conditions the addition of the IS does not result in any displacement reaction (red lines). Upon addition of (a) $\mathrm{Na}_{2} \mathrm{CO}_{3}$ (to reach a $\mathrm{pH}$ of 8) or (b) $\mathrm{NaH}_{2} \mathrm{PO}_{4}$ (to reach a neutral $\mathrm{pH}$ ) strand displacement is triggered, and we observe a fast signal increase (blue lines). Experiments were performed in a $0.01 \mathrm{M}$ Tris buffer +0.01 $\mathrm{M} \mathrm{MgCl}_{2}$, at $25^{\circ} \mathrm{C}$.

and acidic pHs. We did so by taking advantage of the $\mathrm{pH}$ dependence of parallel Hoogsteen interactions and designing clamp-like DNA strands that, by forming a triplex complex under acidic $\mathrm{pHs}$, can trigger or inhibit strand displacement reactions.

We note that alternative DNA or RNA base pairings (Hoogsteen, sugar edges, etc.) and secondary DNA structures (i-motif, G-quadruplex, etc.) are likely more amenable to exogenous control $\left(\mathrm{pH}, \mathrm{Mg}^{2+}\right.$, etc.) than the classic WatsonCrick base pairings. This might open the future to new and exciting possibilities in the field of functional DNA nanotechnology. Compared with other $\mathrm{pH}$-dependent DNA secondary structures (e.g., the i-motif), ${ }^{21,22}$ the use of triplex DNA might allow a better control and a tunable $\mathrm{pH}$-dependency over a wide $\mathrm{pH}$ range. ${ }^{18 \mathrm{~b}}$

The possibility to activate/inhibit the toehold-exchange DNA strand displacement process through a simple change of the solution's $\mathrm{pH}$ appears particularly interesting for several reasons. Since strand displacement has been used to assemble dynamic and static DNA-based nanostructures $4 \mathrm{~b}, 12$ the strategies presented in this work could be adopted to introduce additional control over the formation and functionality of similar DNA nanoarchitectures. For example, our approach would permit in principle to regulate DNA-based origami formation or DNAbased nanodevices' activity exclusively through $\mathrm{pH}$ changes. In addition, since $\mathrm{pH}$ dysregulation is often associated with different diseases (e.g., many cancers are characterized by an inverted $\mathrm{pH}$ gradient between the inside and the outside of cells), ${ }^{23}$ it could be useful to activate the functionality of drug-releasing DNA-based nanomachines only at specific $\mathrm{pH}$ values.

\section{ASSOCIATED CONTENT}

\section{S Supporting Information}

Supporting methods and figures. This material is available free of charge via the Internet at http://pubs.acs.org.

\section{AUTHOR INFORMATION}

\section{Corresponding Author}

francesco.ricci@uniroma2.it

\section{Author Contributions}

"These authors contributed equally.

Notes

The authors declare no competing financial interest.

\section{ACKNOWLEDGMENTS}

This work was supported by Associazione Italiana per la Ricerca sul Cancro, AIRC (project n. 14420) (F.R.), by the European Research Council, ERC (project n.336493) (F.R.), (project no. 269051-Monalisa's Quidproquo) (A.A., M.C.), by the Int. Research Staff Exchange Scheme (IRSES) and by the Nando Peretti Foundation (F.R.).

\section{REFERENCES}

(1) (a) Krishnan, Y.; Bathe, M. Synth. Cell Biol. 2012, 22, 624. (b) Lu, C. H.; Willner, B.; Willner, I. ACS Nano 2013, 7, 8320.

(2) (a) Douglas, S. M.; Bachelet, I.; Church, G. M. Science 2012, 335, 831. (b) Winfree, E.; Liu, F.; Wenzler, L. A.; Seeman, N. C. Nature 1998, 394, 539. (c) Rothemund, P. W. K. Nature 2006, 440, 297.

(3) (a) Turberfield, A. J.; Mitchell, J. C.; Yurke, B.; Mills, A. P., Jr.; Blakey, M. I.; Simmel, F. C. Phys. Rev. Lett. 2003, 90, 118102/1. (b) Bath, J.; Turberfield, A. J. Nat. Nanotechnol. 2007, 2, 275. (C) Mao, C. Nat. Nanotechnol. 2008, 3, 75. (d) Krishnan, Y.; Simmel, F. C. Angew. Chem., Int. Ed. 2011, 50, 3124.

(4) (a) Seelig, G.; Soloveichik, D.; Zhang, D. Y.; Winfree, E. Science 2006, 314, 1585. (b) Zhang, D. Y.; Seelig, G. Nat. Chem. 2011, 3, 103.

(c) Zhang, D. Y.; Winfree, E. J. Am. Chem. Soc. 2009, 131, 17303.

(5) Wickham, S. F. J.; Bath, J.; Katsuda, Y.; Endo, M.; Hidaka, K.; Sugiyama, H.; Turberfield, A. J. Nat. Nanotechnol. 2012, 7, 169.

(6) Han, X.; Zhou, Z.; Yang, F.; Deng, Z. J. Am. Chem. Soc. 2008, 130, 14414.

(7) Liu, M.; Fu, J.; Hejesen, C.; Yang, Y.; Woodbury, N. W.; Gothelf, K.; Liu, Y.; Yan, H. Nat. Commun. 2013, 4, 2127.

(8) Yang, Y.; Liu, G.; Liu, H.; Li, D.; Fan, C.; Liu, D. Nano Lett. 2010, 10, 1393.

(9) Zhu, C.; Wen, Y.; Li, D.; Wang, L.; Song, S.; Fan, C.; Willner, I. Chem.-Eur. J. 2009, 15, 11898.

(10) (a) Elbaz, J.; Lioubashevski, O.; Wang, F.; Remacle, F.; Levine, R. D.; Willner, I. Nat. Nanotechnol. 2010, 5, 417. (b) Genot, A. J.; Bath, J.; Turberfield, A. J. J. Am. Chem. Soc. 2011, 133, 20080.

(11) Sun, Y.-H.; Kong, R.-M.; Lu, D.-Q.; Zhang, X.-B.; Meng, H.-M.; Tan, W.; Shen, G.-L.; Yu, R.-Q. Chem. Commun. 2011, 47, 3840.

(12) (a) Chen, H.; Weng, T.-W.; Riccitelli, M. M.; Cui, Y.; Irudayaraj, J.; Choi, J. H. J. Am. Chem. Soc. 2014, 136, 6995. (b) Wang, F.; Lu, C.-H.; Willner, I. Chem. Rev. 2014, 114, 2881. (c) Baker, B. A.; Mahmoudabadi, G.; Milam, V. T. Soft Matter 2013, 9, 11160.

(13) (a) Zhang, D. Y.; Chen, S. X.; Yin, P. Nat. Chem. 2012, 4, 208.

(14) (a) Xu, X.; Yang, X. Chem. Commun. 2014, 50, 805. (b) Ding, W.; Deng, W.; Zhu, H.; Liang, H. Chem. Commun. 2013, 49, 9953.

(15) Tang, W.; Wang, H.; Wang, D.; Zhao, Y.; Li, N.; Liu, F. J. Am. Chem. Soc. 2013, 135, 13628.

(16) Liu, Z.; Mao, C. Chem. Commun. 2014, 50, 8239.

(17) (a) Jester, S.-S.; Famulok, M. Acc. Chem. Res. 2014, 47, 1700. (b) Kamiya, Y.; Asanuma, H. Acc. Chem. Res. 2014, 47, 1663. (c) Lohmann, F.; Ackermann, D.; Famulok, M. J. Am. Chem. Soc. 2012, 134, 11884. (d) Lohmann, F.; Weigandt, J.; Valero, J.; Famulok, M. Angew. Chem., Int. Ed. 2014, 126, 10540.

(18) (a) Idili, A.; Plaxco, K. W.; Vallée-Bélisle, A.; Ricci, F. ACS Nano 2013, 7, 10863. (b) Idili, A.; Vallée-Bélisle, A.; Ricci, F. J. Am. Chem. Soc. 2014, 136, 5836.

(19) Ohmichi, T.; Kawamoto, Y.; Wu, P.; Miyoshi, D.; Karimata, H.; Sugimoto, N. Biochemistry 2005, 44, 7125.

(20) Soto, A. M.; Loo, J.; Marky, L. A. J. Am. Chem. Soc. 2002, 124, 14355 .

(21) Li, T.; Ackermann, D.; Hall, A. M.; Famulok, M. J. Am. Chem. Soc. 2012, 134, 3508. Li, T.; Famulok, M. J. Am. Chem. Soc. 2013, 135, 1593.

(22) Modi, S.; Nizak, C.; Surana, S.; Halder, S.; Krishnan, Y. Nat. Nanotechnol. 2013, 8, 459.

(23) Webb, B. A.; Chimenti, M.; Jacobson, M. P.; Barber, D. L. Nat Rev Cancer 2011, 11, 671 . 